\title{
Identification of up-regulated genes in human uterine leiomyoma by suppression subtractive hybridization
}

\author{
Bin LI, Yong Lian ZHANG* \\ State Key Laboratory of Molecular Biology, Institute of Biochemistry and Cell Biology, Shanghai Institutes for \\ Biological Sciences, Chinese Academy of Sciences, 320 Yueyang Road, Shanghai 200031, China
}

\begin{abstract}
In searching for differentially expressed genes in human uterine leiomyomas (ULs), suppression subtractive hybridization was used to construct an UL up-regulated library, which turned out to represent 88 genes. After two rounds of screening by reverse Northern analysis, twenty genes were proved to be upregulated, including seventeen known genes and three genes with unknown function. All these genes were firstly associated with UL. Three genes with notable difference were selected for Northern confirmation. Our results proved the authenticity of the twenty genes. One gene named Phospholipase A2 (PLA2) showed up-regulation in $4 / 6$ of the patients and investigation of tissue distribution indicated that it had obvious expression in prostate, testis, liver, heart and skeletal muscle.
\end{abstract}

Key words: human uterine leiomyoma, suppression subtractive hybridization, up-regulated gene in uterine leiomyoma, screening library.

\section{INTRODUCTION}

As the most common reproductive tract neoplasm in premenopausal women, Uterine Leiomyoma (UL) is a kind of benign tumor with multi-gene involved [1]. Finding and studying these genes involved have been a long need for developing non-surgery therapy and prevention methods. As UL rarely appears in postmenopausal women, many efforts have been concentrated on estrogen and progesterone as well as their receptors and have shown their close relationship with UL[2-6]. Meanwhile, cytogenetic studies have shown that more than $60 \%$ of leiomyomas possess a normal female karyotype and that $30 \%$ have clonal chromosomal aberrations[7],[8]. A variety of aberrations have been demonstrated on chromosomes, including chromosomes $1,2,4,6,7$, $10,12,13,14,19,22$ and X[9-18]. In particular,

* Corresponding author: Tel. 8621-6437-4430 Ext 5293; Fax. 86216433-8357; E-mail: yonglz@sunm.shcnc.ac.cn Received May-8-2002 Revised July-16-2002 Accepted July-182002 rearrangements of $6 p, \operatorname{del}(7 q)$ and $t(12: 14)$ have emerged as primary abnormalities. However, no gene has been proved to be the direct cause of UL yet. Besides, although many genes involved, no profile of genes associated to UL has been reported. The mRNA differential display (DD) and the suppression subtractive hybridization ( $\mathrm{SSH}$ ) techniques have been reported to be powerful tools in searching for genes expressed at different levels in two samples compared[19], [20]. We used both approaches to study the differentially expressed genes in UL. However, DD showed low positive rate in our previous work[21]. Here we report the use and validation of SSH to study genes related to UL and the finding of twenty genes up-regulated in UL, including seventeen known genes and three genes with unknown function, which were firstly associated with UL.

\section{MATERIALS AND METHODS}

Patients 
Seven patients with uterine leiomyoma at the age of 24 to 45 years old were hysterectomized in Obstetrics/Gynecology Hospital, Medical Center of Fudan University and Changzhen Hospital. Under their approval, tissues separately from uterine leiomyoma and matched normal myometrium were snap frozen immediately after removal and kept at $-70{ }^{\circ} \mathrm{C}$ for further study.

\section{RNA preparation}

Total RNA was isolated from seven pairs of leiomyomas and matched myometrium by the single-step guanidine isothiocyanate method[22]. Poly (A) ${ }^{+}$RNA was extracted from one pair of total RNAs using PolyATtract ${ }^{\circledR}$ RNA Isolation System III kit (Promega). RNAs are quantified by GeneQuant RNA/DNA calculator (Pharmacia Biotech) and qualified by formaldehyde denaturing agarose gel electrophoresis.

\section{Suppression subtractive hybridization}

Suppression subtractive hybridization was performed as described in CLONTECH PCR-Select ${ }^{T M}$ cDNA Subtraction Kit User Manual (CLONTECH). Double-stranded cDNAs were synthesized separately from $2 \mu \mathrm{g}$ of Poly (A) RNAs extracted from leiomyoma and matched normal myometrium using reagents provided in Kit. Complementary DNA from leiomyoma used as driver was digested with Rsa I (a 4-base-cutting restriction enzyme) to get relatively short cDNA sequences. It was divided into two parts and then they were ligated to two different adaptors (which bind only to the 5' end of cDNA). In the presence of excess cDNAs from myometrium (Ras I digested, as tester), the two parts were heated to be denatured and then annealed separately. During this step the sequences that were common to the tester and the driver formed hybrids. Furthermore, in the presence of freshly denatured tester these two parts were mixed together without denaturation. Sequences that expressed only in leiomyoma reassociated that formed double-stranded cDNAs with different adaptors at both ends, which enable them to be amplified exponentially during PCR. The suppression PCR was performed as described in CLONTECH PCR-Select ${ }^{T M}$ cDNA Subtraction Kit User Manual (CLONTECH). In primary PCR, $1.0 \mu \mathrm{l}$ PCR primer $1(10 \mu \mathrm{M})$, $2.5 \mu \mathrm{l} 10 \times$ PCR buffer, $1.6 \mathrm{ml}$ dNTPs $(2.5 \mathrm{~m} \mathrm{M}), 0.15 \mathrm{ml}$ Ex TaqTM (Takara) were added with the final volume of $25 \mu \mathrm{l}$. The reaction was performed on Perkin-Elmer DNA Thermal Cycler 480 for 35 cycles in $94{ }^{\circ} \mathrm{C}$ for $30 \mathrm{sec}, 66^{\circ} \mathrm{C}$ for $30 \mathrm{sec}, 72^{\circ} \mathrm{C}$ for $1.5 \mathrm{~min}$. In secondary PCR, PCR primer 1 was replaced with $1.0 \mu \mathrm{l}$ Nested PCR primer $1(10 \mu \mathrm{M})$ and $1.0 \mu \mathrm{l}$ Nested PCR primer $2 \mathrm{R}(10 \mu$ M). The PCR reaction was performed for 20 cycles in $94{ }^{\circ} \mathrm{C}$ for 30 sec, $68^{\circ} \mathrm{C}$ for $30 \mathrm{sec}, 72{ }^{\circ} \mathrm{C}$ for $1.5 \mathrm{~min}$, with a final elongation cycle for $30 \mathrm{~min}$ at $72{ }^{\circ} \mathrm{C}$. In addition, because of the kinetics of subtractive hybridization and the suppression PCR, which is based on the specific PCR primer structure, the concentrations of the high and low abundance differentially expressed cDNAs were equalized.

\section{Reverse Northern analysis (differential screening)}

Plasmids of interested clones were prepared and used as PCR templates. All PCR products were electrophoresed to verify the presence of the inserts and were dot-blotted onto two duplicate nylon membrane sets. First strand cDNAs were incorporated with ${ }^{32} \mathrm{P}$-dATP during reverse transcription from total RNAs (derived from leiomyoma and matched normal myometrium) by using oligo (dT) as primer. They were hybridized separately to those two membrane sets. Up-regulated clones were sequenced, and were dot-blotted onto two duplicate nylon membranes (with five dots of G3PDH as positive and quantitative control). Another reverse Northern analysis was performed using messenger RNAs as probe templates. False-positive clones were further ruled out.

\section{Northern analysis}

Several clones confirmed by reverse Northern were selected for further Northern confirmation. PCR products of them were gel purified and semi-quantified. The radio-labeling of probe and Northern Blot were performed as described in our reported work[21].

\section{RESULTS}

Construction of human UL up-regulated cDNA library

The brief steps from the construction to screening of the library were summarized in Fig 1. After cDNAs derived from UL were subtracted with cDNAs from myometrium, suppression PCR was performed to amplify cDNAs up-regulated in UL while the common sequences in both tissues were suppressed. The suppression subtraction efficiency was evaluated by PCR, using a housekeeping gene (G3PDH) as internal reference. As showed in Fig 2a, the PCR product of G3PDH can be seen over ten cycles later in the subtracted samples, which was in line with the criteria of the kit. Then the suppression PCR products were ligated into T-easy vector, and transformed into E. coli. About 350 white colonies were picked up from the plates for overnight culture. Twelve clones were selected at random for check and all were proved to have inserts with the average size 300bp (Fig 2b). Thus a subtracted library was constructed.

\section{Screening of leiomyoma related genes}

As described in Fig 1, plasmid DNAs were prepared from clones in subtracted library and used as PCR templates for amplification of inserts. The PCR products were electrophoresed to verify the presence of the inserts and 288 of them with single sharp band were dot-blotted onto three pairs of nylon membranes (96-well/each membrane). First strand cDNAs were labeled with ${ }^{32} \mathrm{P}$-dATP during reverse 


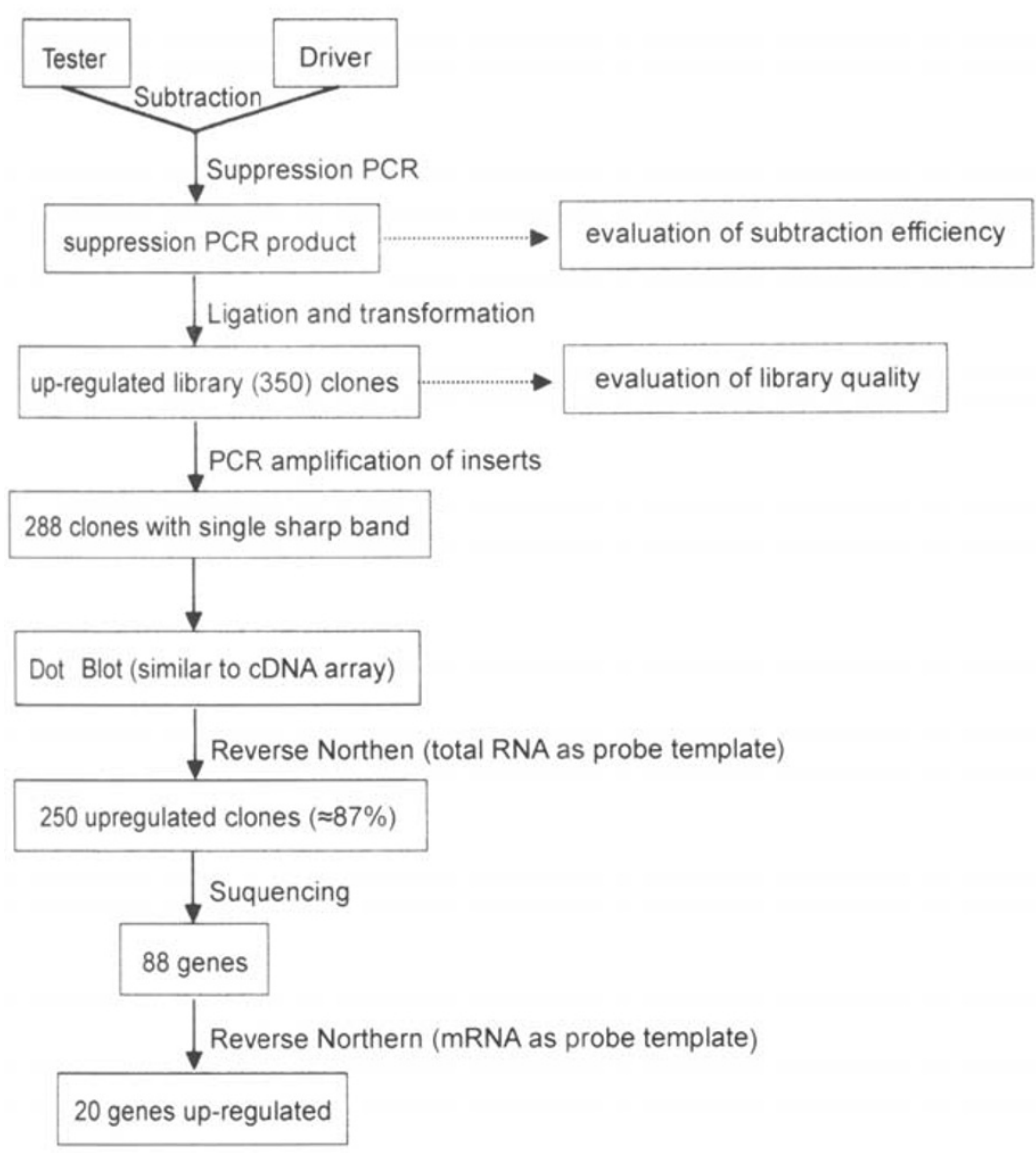

Fig 1. Diagram of construction and screening of the upregulated library. transcription by using total RNAs from leiomyoma and matched normal myometrium as templates. They were hybridized separately to those two membrane sets as primary screening. Nearly $87 \%$ clones (250) were showed to be up-regulated (data not shown). These clones were sequenced (because there are many repeated clones in the library, each time 10 clones were sequenced and redundant clones of these 10 were gotten rid of by Southern analysis; this step was repeated till no clone left) and it turned out to represent 88 genes. All these 88 genes were dot-blotted onto two duplicate nylon membranes (with five dots of G3PDH as positive and quantitative control). For eliminating the false-positive clones and enhancing the specificity, another reverse Northern analysis was performed using messenger RNAs as probe templates (Fig 3). Using G3PDH as control, 20 genes were proved to be up-regulated in UL (Tab 1 and 2), with the up-regulation fold from 0.5 to 11 .

Tab 1. The catalog of known genes overexpressed in human UL

\begin{tabular}{|c|c|c|c|}
\hline Clone ID & Name of protein/gene & Accession & Chromosome \\
\hline 004/E1* & Human nonmuscle myosin heavy chain-B (MYH10) & M69181 & $17 q 13$ \\
\hline $034 / \mathrm{E} 4^{*}$ & Human SOD-2 gene for manganese superoxide dismutase & X65965 & $6 q 25$ \\
\hline 056/G6 & Human ferritin $\mathrm{H}$ chain & M11146 & $11 q 13$ \\
\hline 066/G7* & Human dioxin-inducible cytochrome P450 (CYP1B1) & U56438 & $2 \mathrm{p} 21-22$ \\
\hline $073 / \mathrm{F} 11^{*}$ & Human secretogranin II (chromogranin C) (SCG2) & M25756 & 2 \\
\hline $079 / \mathrm{E} 6 *$ & Human $\mathrm{Ca}^{2+}$-independent Phospholipase $\mathrm{A}_{2}$ (PLA2) & NM-004905 & $\operatorname{lq} 23.3$ \\
\hline 103/G9 & Human MAX-like bHLHZIP protein (MLX) & XM-008397 & 17 \\
\hline $107 / \mathrm{H}^{*}$ & Human mitochondrial aldehyde dehydrogenase $\mathrm{x}$ & M63967 & 9 \\
\hline 134/H7 & Human mitochondrion cytochrome oxidase subunit II (COII) & $\mathrm{X} 15759$ & l \\
\hline 240/G12 & Human PEG1/MEST & NM-002402 & $7 q 32$ \\
\hline 293/H11 & Human RAS-related protein RAB-23 & AF161486 & 6 \\
\hline 014/F1* & Human ribosomal protein L19 (RPL19) & NM-000981 & $17 q 11.2-q 12$ \\
\hline 047/F9 & Human mitochondrial ribosomal protein S23 (MRPS23) & XM-008155 & 17 \\
\hline 071/F5 & Human ribosomal protein S25 (RPS25) & NM-001028 & $11 \mathrm{q} 23.3$ \\
\hline 081/G1 & Human ribosomal protein S15 (RPS15) & NM-001018 & $19 \mathrm{p} 13.3$ \\
\hline $271 / \mathrm{H} 4^{*}$ & Human ribosomal protein L27 (RPL27) & NM-000988 & 17q21.1-q21.2 \\
\hline 290/H5 & Human ribosomal protein L9 (RPL9) & NM-000661 & $4 \mathrm{p} 13$ \\
\hline
\end{tabular}

Note: clones that have been upregulated obviously are indicated by asterisk. 
Tab 2. The function-unknown genes with up-regulated expression discovered in human UL

\begin{tabular}{|c|c|c|c|c|}
\hline Clone ID & Name of protein/gene & Accession & Chromosome & Motif \\
\hline 027/E10 & Human CGI-111 protein & AF151869 & $5 q$ & No \\
\hline 043/F 8 & $\begin{array}{l}\text { Human calpain-like } \\
\text { protease CANPX }\end{array}$ & AJ000388 & $\mathrm{Xq} 2$ & $\begin{array}{l}\text { EF-hand calcium-binding domain; } \\
\text { Eukaryotic thiol (cysteine) } \\
\text { proteases cysteine active site }\end{array}$ \\
\hline 049/B6* & Human DC31 & AF 255793 & 1 & No \\
\hline
\end{tabular}

Note: clones that have been up-regulated obviously are indicated by asterisk.
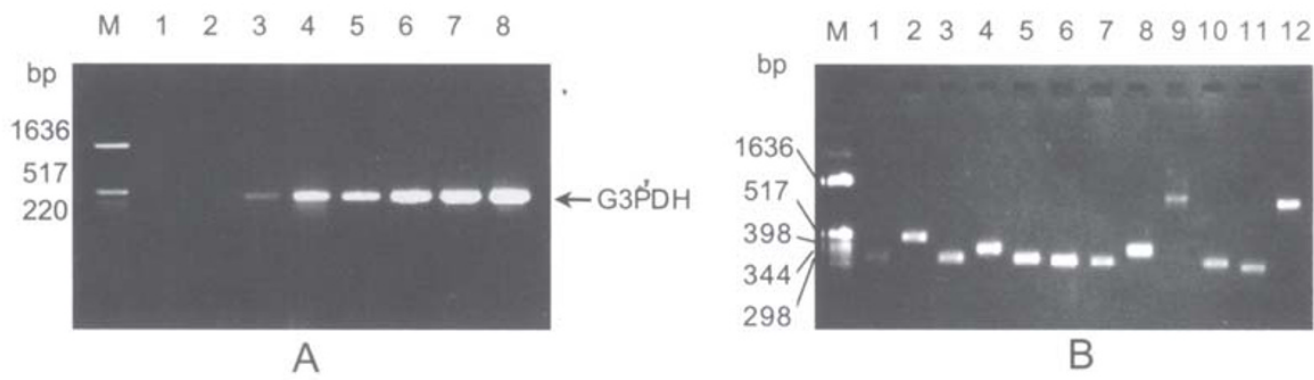

Fig 2. A. Reduction of G3PDH abundance by PCR-Select subtraction. PCR was performed on subtracted (Lanes 1-4) and unsubtracted (Lanes 5-8) suppression PCR product with G3PDH 5' and 3' primers included in cDNA Subtraction Kit. Lane M: pBR322+hinf1; Lane 1\&5: 20 cycles; Lane 2\&6: 25 cycles; Lane 3 \&7: 30 cycles; Lane 4 \&8: 35 cycles. B. PCR was performed using plasmids from twelve clones as template. The parameters are the same as suppression PCR described in User Manual except that 30 cycles were used.
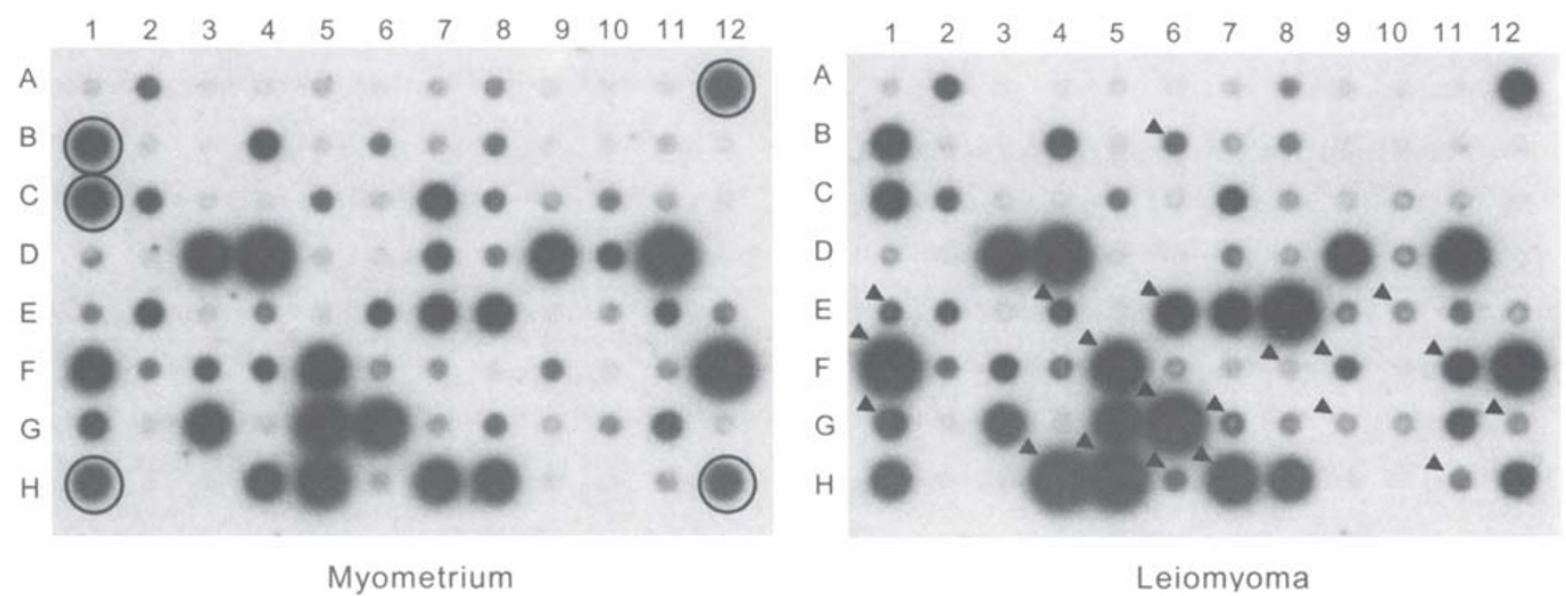

Leiomyoma

Fig 3. Differentially expressed genes are detected by Reverse Northern analysis using mRNAs as probe template. Two sets of blots are made with equal quantity of PCR products. Positive controls (G3PDH) are marked with circles. Genes that have been up-regulated are shown by arrows.

\section{Confirmation of Northern analysis}

Three genes (034/E4, 073/F11, 079/E6) with notable difference were selected from those indicated to be up-regulated for further confirmation by Northern analysis. They all gave signals of upregulation in UL (Fig 4a), which coincides with the result gained from Reverse Northern analysis (Fig 3 ). We even picked up two genes that showed no difference in Reverse Northern for confirmation by Northern, and their results matched well too (data not shown). That means the genes found by Reverse Northern Analysis were reliable. About the clone 079/E6, we found it is up-regulated notably in most samples (4/6), which showed its close relationship with UL (Fig 4b). We also found there are notably difference between individuals we investigated, which means not only expressions of the same gene among different patients but also the expression ratio of genes are different. Investigation of tissue distribution of 079/E6 showed that it had obvious expres- 


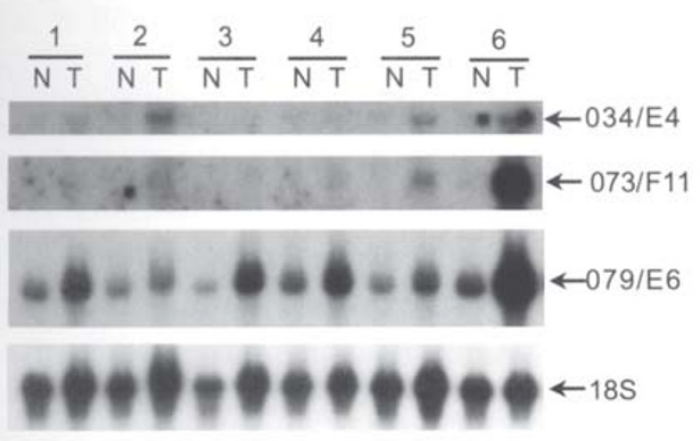

A

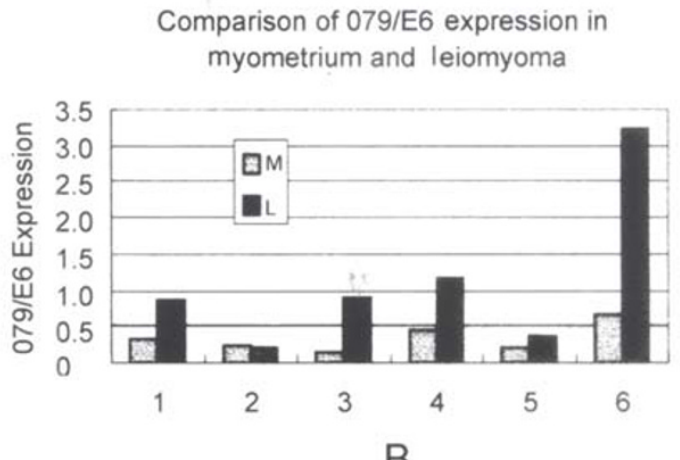

B

Fig 4. A. Northern analysis of clone 034/E4, 073/F11 and 079/E6 were done with six pairs of RNAs from six patients (number 1-6, they were hysterectomized separately on day 8, 32, 9, 9, 16, 13 to their last menses). And the results were normalized by $18 \mathrm{~S}$. Lane $\mathrm{T}$ corresponds to total RNA from leiomyomas; lane $\mathrm{N}$ represents that from matched myometrium. Sample 6 was the one we used to construct the library. B. Expressions of 079/E6 in six patients' myometrium and leiomyoma were normalized by 18S and compared mutually. Y-axis represents the relative quantity of 079/E6 expression compared with $18 \mathrm{~S}$. X-axis represents the six pairs' samples used. M represents that in myometrium while $\mathrm{L}$ represents that in leiomyoma.

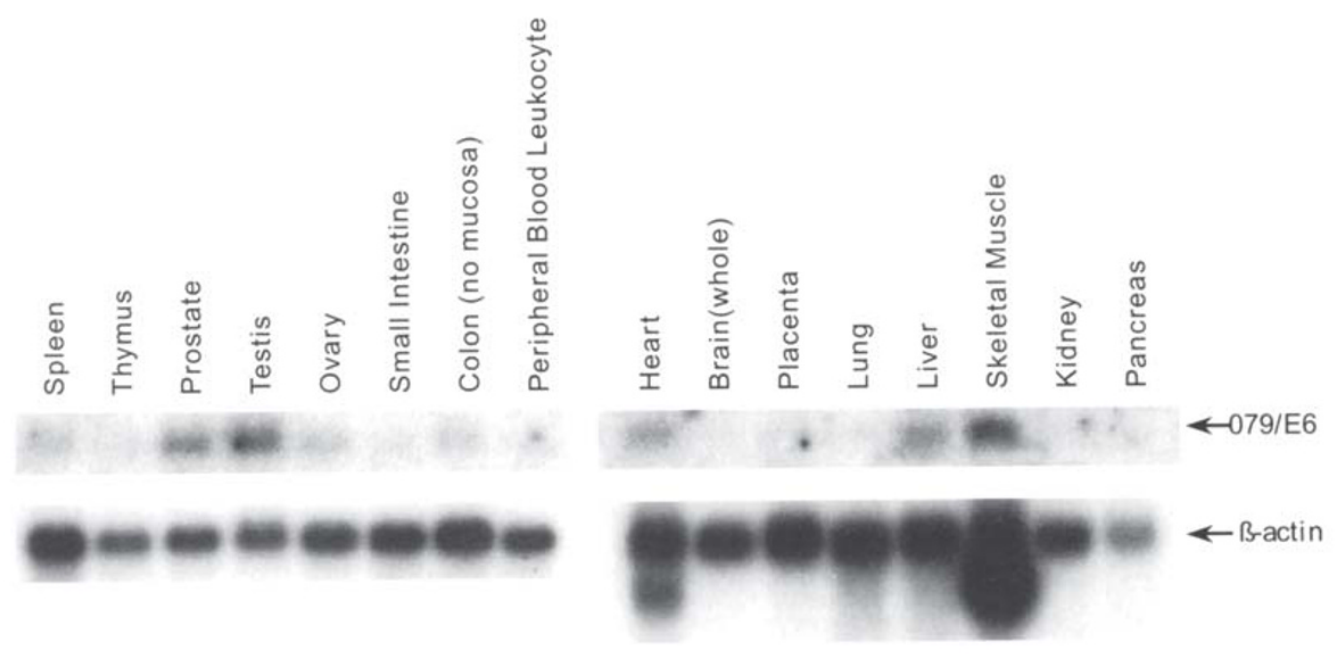

Fig 5. Tissue distribution of clone 079/E6.

sion in prostate, testis, liver, heart and skeletal muscle, which indicated its relationship to reproduction, motility and metabolism (Fig 5).

\section{Analysis of genes up-regulated in leiomyoma}

Searching in GenBank by program Blastn using sequences of the 20 genes, we found 17 of them have known function and the other three genes are functionally unknown but with known full coding sequences (Tab 1 and 2). These known genes, including Phospholipase $\mathrm{A}_{2}\left(\mathrm{PLA}_{2}\right)$, MAX-like protein $\mathrm{x}$
(MLX), nonmuscle myosin heavy chain B (NMMHCB), ribosomal protein (L19, S25, S15, L27, L9, MRPS23), etc., were firstly recognized to have high expression in UL. By searching in human genome database and published papers, we found the possible position on chromosome for nineteen genes (Tab 1 and 2). Searching at amino acid level revealed that 027/E10 has high homology (97\% in 185aa homologous region, $91 \%$ in full length) with a tumorrelated protein in Mus musculus. CD (Conserved Domain) Search indicates that it may have some re- 
lationship with Isochorismatase family. $043 / \mathrm{F} 8$ is a new member of calpain protein family. Not like other members, it does seem to have protease activity as it has lost the active site residues. It was reported to express only in placenta before, but our data showed its presence in UL. No homologue has been found for 049/B6 at $\mathrm{Nt}$ and aa level.

DISCUSSION After being reported in 1996[23], tens of papers have reported successful use of SSH method in identifying differential cDNAs. In our lab, we have identified 20 genes up-regulated in UL in only one round of SSH, including one gene (043/ F8) with very low abundance. In recent years a technique with high throughput, termed gene chip, has showed strong power in screening differential genes. Compared with $\mathrm{SSH}$, it is more rapid and effective. But limited by the cDNAs printed on the chip, those tissue-specific or new genes not presented on chip can not be checked out. And compared with DD we used, SSH has shown lower false positive rate. Also there are some limitations that can' $t$ be overcome by SSH itself. However, in our experience, reverse Northern technique especially when mRNAs were used as probe template showed strong power in getting rid of false positives. That was why nearly all the 20 up-regulated genes identified by reverse Northern were also proved by Northern analysis. The low efficiency of adaptors ligated to cDNAs greatly reduces the number of genes that should have been screened out. We only got a nearly $20 \%$ ligation efficiency in our experiment. Although 20 genes we have gotten, we believe there are still many genes to be found out. It is worthwhile pointing out that we used the samples from one patient to construct the library, which may bring some limitations (e.g. individual difference, pathological progression difference of the tumor). As shown in Fig 4a, the Northern result of sample 6 matched well with that in reverse Northern, but not so consistently with that in other samples. We believe using mixture mRNA from several patients as starting material may to some extent overcome this problem.

In Tab 1 there are 17 genes with known function. About two thirds of them can be grouped into two categories: protein expression (014/F1, 047/F9, 071/ F5, 081/G1, 271/H4, 290/H5), metabolism (034/E4, 066/G7, 079/E6, 107/H6, 134/H7). Their high expression in UL indicates the vigorous synthetic and metabolic reactions happening there, which is necessary for neoplasm proliferation. Other genes identified here certainly are not by chance. They function in their own way. As to the three genes with unknown function, homology comparisons at $\mathrm{Nt}$ and aa levels in GenBank gave us some information. However, these informations are far from enough to explain the function of these genes. And their function and relationships with UL have to be clarified by further experiment.

It is not surprising that only one gene we cloned (240/G12) is mapped to chromosome 7, one of those chromosomes where abnormalities were often reported. In fact, the sample we used to construct the library had a normal karyotype as that in most patients. There is one thing especially arousing our interest. We found that five out of the 17 known genes had been mapped to chromosome 17 (Tab 1). Although many chromosomes involved, no aberration has been reported to occur on chromosome 17 in UL yet. But numerical aberrations on chromosome 17 had been reported in many other tumors, including breast and ovarian cancers[24]. It is worthwhile investigating the reason why so many genes located on chromosome 17 are up-regulated. Besides, in this experiment we provided 20 up-regulated genes that may be involved in UL for further investigation.

\section{ACKNOWLEDGEMENTS}

We thank Dr. Naihe Jin (Institute of Biochemistry and Cell Biology, Shanghai Institute for Biological Science, Chinese Academy of Sciences) for the SSH Kit he provided and Dr. Jin Yu (Obstetrics/ Gynecology Hospital, Medical Center of Fudan University) for part of the human samples she presented.

This work was supported by National Natural Science Fundation of China No. 39700148 and Life Science Special fund of CAS supported by Chinese Minisery of Finance.

\section{REFERENCES}

[1] Gesenhues T, Hackenberg R, Diechert U, Duda V, Sturm G, Schulz KD. New possibilities for differentiated therapy of leiomyoma of the uterus using the $\mathrm{GnRH}$ agonist zoladex. Geburtshilfe. Frauenheilkd 1989; 49 Suppl 1: 96-8.

[2] Andersen J, Grine E, Eng CL Y, et al. Expressin of connexin43 inhuman myometrium and leiomyoma. Am J Obstet 
Gynecol 1993; 169:1266-76.

[3] Rein MS, Barbieri RL, Friedman AJ. Progesterone: a critical role in the pathogenesis of uterine myomas. Am J Obstet Gynecol 1995; 172(1 Pt 1):14-8.

[4] Wu J, Cheng Y. Research on the relationship between estrogen receptor, progesterone receptor, cell proliferation associated antigen in uterine leiomyoma and nuclear body density of myoma, serum reproductive hormone concentrations. Chung Hua Fu Chan Ko Tsa Chih 1995; 30(10):603-7.

[5] Brandon DD, Erickson TE, Keenan EJ, Strawn EY, Novy MJ, Burry KA, et al. Estrogen receptor gene expression in human uterine leiomyomata. J Clin Endocrinol Metab 1995; 80(6): 1876-81.

[6] Ichimura T, Kawamura N, Ito F, Shibata S, Minakuchi K, Tsujimura A, Umesaki N, Ogita S. Correlation between the growth of uterine leiomyomata and estogen and progesterone receptor content in needle biopsy specimens. Fertil Steril 1998; 70(5):967-71.

[7] Mark J, Havel G, Grepp C, Dahlenfors R, Wedell B. Cytogenetical observations in huamn benign uterine myomas. Anticancer Res 1988; 8:621-6.

[8] Pandis N, Heim S, Bardi G, Floderus U M, Willen H, Mandahl N, Mitelman F. Chromosome analysis in 96 uterine leiomayomas. Cancer Genet Cytogenet 1991; 55:118.

[9] Sait SN, Dal Cin P, Ovanessoff S, Sandberg AA. A uterine leiomyoma showing both $\mathrm{t}(12 ; 14)$ and $\operatorname{del}(7)$ abnormalities. Cancer Genet Cytogenet 1989; 37(2):15761.

[10] Vanni R, Nieddu M, Paoli R, Lecca U. Uterine leiomyoma cytogenetics. I. Rearrangements of chromosome 12. Cancer Genet Cytogenet. 1989; 37(1):49-54.

[11] Vanni R, Dal Cin P, Van Den Berghe H. Is the chromosome band 1p36 another hot-spot for rearrangements in uterine leiomyoma? Genes Chromosomes Cancer 1990; 2(3):255-6

[12] Nibert M, Heim S. Uterine leiomyoma cytogenetics. Genes Chromosomes Cancer 1990; 2(1):3-13.

[13] Nilbert M, Heim S, Mandahl N, Floderus UM, Willen H, Mitelman F. Characteristic chromosome abnormalities, including rearrangements of $6 p, \operatorname{del}(7 q),+12$, and $t(12$; 14), in 44 uterine leiomyomas. Hum Genet 1990; 85(6):
605-11.

[14] Nilbert M, Heim S, Mandahl N, Floderus UM, Willen H, Mitelman F. Trisomy 12 in uterine leiomyomas. A new cytogenetic subgroup. Cancer Genet Cytogenet 1990; 45 (1):63-6.

[15] Vanni R, Lecca U, Faa G. Uterine leiomyoma cytogenetics. II. Report of forty cases. Cancer Genet Cytogenet 1991; 53(2):247-56.

[16] Stern C, Deichert U, Thode B, Bartnitzke S, Bullerdiek J. Cytogenetic subtyping of 139 uterine leiomyoma. Geburtshilfe Frauenheilkd 1992; 52(12):767-72.,p> [17] Ozisik YY, Meloni AM, Surti U, Davare J, Sandberg AA. Inversion (X)(p22q13) in a uterine leiomyoma. Cancer Genet Cytogenet 1992; 61(2):131-3.

[18] Hayashi S, Miharu N, Okamoto E, Samura O, Hara T, Ohama K. Detection of chromosomal abnormalities in uterine leiomyoma using conventional cytogenetic method and interphase fluorescence in situ hybridization. Cancer Genet Cytogenet. 1996; 89(2):98-104.

[19] Hess J, Laumen H, Wirth T. Application of differential cDNA screening techniques to the identification of unique gene expression in tumours and lymphocytes. Curr Opin Immunol 1998; 10(2):125-30.

[20] von Stein OD. Isolation of differentially expressed genes through subtractive suppression hybridization. Methods Mol Biol 2001; 175:263-78.

[21] Li B, Sun M, He B, Yu J, Zhang YD, Zhang YL. Identification of differentially expressed genes in human uterine leiomyomas using differential display. Cell Research 2002; 12(1):39-45.

[22] Chomezynski P, Sacchi N. Single-step method of RNA Isolation by acid guanidinium thiocyanate-phenol-chloroform extraction. Anal Biochem 1987; 162:156-9.

[23] Diatchenko L, Lau YF, Campbell AP, Chenchik A, Moqadam F, Huang B, et al. Suppression subtractive hybridization: a method for generating differentially regulated or tissue-specific cDNA probes and libraries. Proc Natl Acad Sci USA 1996 Jun 11; 93(12):6025-30.

[24] Engel H, Kleespies C, Friedrich J, Breidenbach M, Kallenborn A, Schondorf T, et al. Detection of circulating tumour cells in patients with breast or ovarian cancer by molecular cytogenetics. Br J Cancer 1999; 81(7):116573. 